\title{
DOSSIÊ BAUDELAIRE E A NATUREZA DA LINGUAGEM POÉTICA
}

\section{DOSSIER BAUDELAIRE AND THE NATURE OF THE POETIC LANGUAGE}

Sabrina Vier

Universidade do Vale do Rio dos Sinos, Unisinos, São Leopoldo, RS, Brasil

Resumo: Benveniste (1989) defende que todo sistema deve especificar a natureza do sentido produzido. Por meio do estudo de fólios do Dossiê Baudelaire (LAPLANTINE, 2008), objetiva-se problematizar a natureza da linguagem poética. Os resultados apontam que o material do poeta é a palavra-escrita e a palavra-ícone, a unidade do poema. Assim, o poeta dá a emoção e não diz a emoção: a palavra-ícone (imagem e emoção) instaura correspondências suscitadas pela emoção e pela experiência.

Palavras-chave: Dossiê Baudelaire; linguagem poética; natureza.

Abstract: Benveniste (1989) defends that every system must specify the nature of the meaning produced. By means of the study of folios in the Baudelaire Dossier (LAPLANTINE, 2008), this study aims to problematize the nature and the functioning of the poetic language. The results show that the poet's material is the written word, and the icon word, the unity of the poem. Iconicity - the act of iconizing emotion - is the poem's working principle. Thus, the poet gives the emotion and does not say the emotion: the icon word (image and emotion) establishes correspondences raised by emotion and by experience.

Key-words: Baudelaire Dossier; poetic language; nature.

\section{Consideraçóes Iniciais}

Em $1^{\circ}$ de dezembro de 1969, Émile Benveniste conferia a primeira e última - aula de um curso que ministraria no ano letivo de 1969-1970 no Collège de France. Cinco dias depois, Benveniste sofreria um acidente vascular cerebral que o paralisaria e o deixaria afásico (COQUET; FENOGLIO, 2014). Em 2012, após trinta e seis anos da morte de Benveniste, vêm a público, por meio da obra Dernières leçons (BENVENISTE, 2012), as notas preparatórias do linguista para esse curso no Collège de France - misturadas 
com algumas para o simpósio em Varsóvia - junto a anotaçôes de alunos ${ }^{1}$.

Das aulas presentes nessa obra, interessa-me, em especial, a aula do dia $1^{\circ}$ de dezembro - que conta com anotaçôes de dois alunos, Jean-Claude Coquet e Claudine Normand. Segundo Coquet e Fenoglio (2014, p. 84), as notas preparatórias e as anotaçóes dos alunos deixam ver que as noçóes semântico-semiótico eram o foco dessa primeira aula: "[...] ela prepara e introduz essa problemática que Benveniste não terá tempo de apresentar a seu público".

Meu interesse se dá pela referência ao poeta Charles Baudelaire na anotação de um aluno: "Baudelaire intuiu essa relação de homologia em seu poema Correspondences" (BENVENISTE, 2014, p. 190). Em Problemas de Linguistica Geral II, o poeta também comparece - e somente uma vez - no artigo Semiologia da Língua, de 1969: "Les perfums, les couleurs et les sons se répondent'. Estas 'correspondências' não estão senão em Baudelaire, elas organizam seu universo poético e a imagem ${ }^{2}$ que o reflete" (BENVENISTE, 2008, p. 61).

Poemas de Baudelaire de As Flores do Mal e o discurso poético são tema de 367 notas de Benveniste e geraram o que conhecemos hoje por Dossiê Baudelaire (doravante DB). Esse material está conservado na Biblioteca Nacional da França, vindo a público de duas maneiras: em 2008, via tese de doutorado da linguista Chloé Laplantine (LAPLANTINE, 2011a, 2011b) e, em seguida, em 2011, via publicação da editora Lambert-Lucas (BENVENISTE, 2011).

Coquet e Fenoglio (2014, p. 82) pontuam que os suportes das notas correspondentes à última aula do dia $1^{\circ}$ de dezembro de 1969 "[...] são muito heteróclitos: diferentes papéis, diferentes formatos". Os linguistas esclarecem que foram necessárias várias leituras do conjunto das notas e das notas dos alunos para estabelecer uma coerência e legibilidade. Conforme Vier (2016), igualmente complexa é a leitura das notas do DB: também encontramos diferentes papéis, diferentes formatos, e nenhum aluno que possa auxiliar para estabelecer alguma coerência ou legibilidade. Nem mesmo encontramos alguma sequência de reflexão do linguista entre as notas.

Fenoglio (2013, p. 27) chama atenção para o fato de que esse material

${ }^{1}$ Em 2014, a obra é traduzida para o português brasileiro (BENVENISTE, 2014).

2Utilizo aqui a versão em francês, "[...] et l'imagerie qui le reflete" (BENVENISTE, 2008, p. 61), pois a versão brasileira apresenta "[...] e a criaçâo que o reflete" (BENVENISTE, 1989, p. 62). 
está sem texto ${ }^{3}$ e, nesse sentido, questiona: seria “[...] um projeto de arte ou de ensaio?”. Esse questionamento advém de um manuscrito do linguista e, a partir dele, a autora entende que essas folhas poderiam não gerar um artigo. Dessa forma, pouco interessa à Genética Textual esse material, pois não é possível com ele uma análise linguística visando ao processo de reconstituição genética. Laplantine (2011a, 2011b), ao contrário, defende que o DB deixa ver o estudo para a escrita de um artigo. Isso porque Benveniste tinha o hábito de fazer listas dos livros ou artigos que pretendia escrever. Dentre os manuscritos do DB, encontramos uma dessas listas com data de 1967: “[...] 'Langages/ (A língua de Baudelaire)"” (LAPLANTINE, 2011a, p. 8). Sabemos que esse artigo foi solicitado por Roland Barthes que organizou o número 12 (publicado em dezembro de 1968) da revista Langages, intitulada Linguistica e literatura. No entanto, esse artigo jamais foi publicado ou mesmo posto em rascunho (LAPLANTINE, 2011b).

Para além da discussão de as notas comporem um estudo que visava a um artigo ou não, pelas indicaçōes presentes em Semiologia da Língua e nas anotaçóes das últimas aulas, tenho por hipótese de Benveniste buscava, no DB, a homologia intuída por Baudelaire (VIER, 2016). E é por meio das relaçóes de interpretância que Benveniste produziu, em sua escrita, ao buscar as homologias intuídas por Baudelaire, que objetivo, neste texto, problematizar a natureza da linguagem poética que a escrita de Benveniste deixa ver em notas do DB.

Para isso, organizo este texto em três etapas: primeiramente, esclarecerei de que forma busco as relaçôes de interpretância que Benveniste produziu em sua escrita, ou seja, apresentarei uma possibilidade de leitura dos manuscritos presentes no DB. Em seguida, compartilho um percurso de leitura em busca da natureza da linguagem poética. Por fim, teço algumas consideraçôes finais.

\section{O poema ausente-presente em Semiologia da Língua}

Dessons (2009) defende que o poema está ausente-presente em Semiologia da Língua, pois, em um fólio do DB, ao falar das artes plásticas e da música, como também ocorre no artigo, Benveniste o faz junto ao poema:

3Para Fenoglio (2013), não há texto porque não é possível comparar o manuscrito com o texto final. 


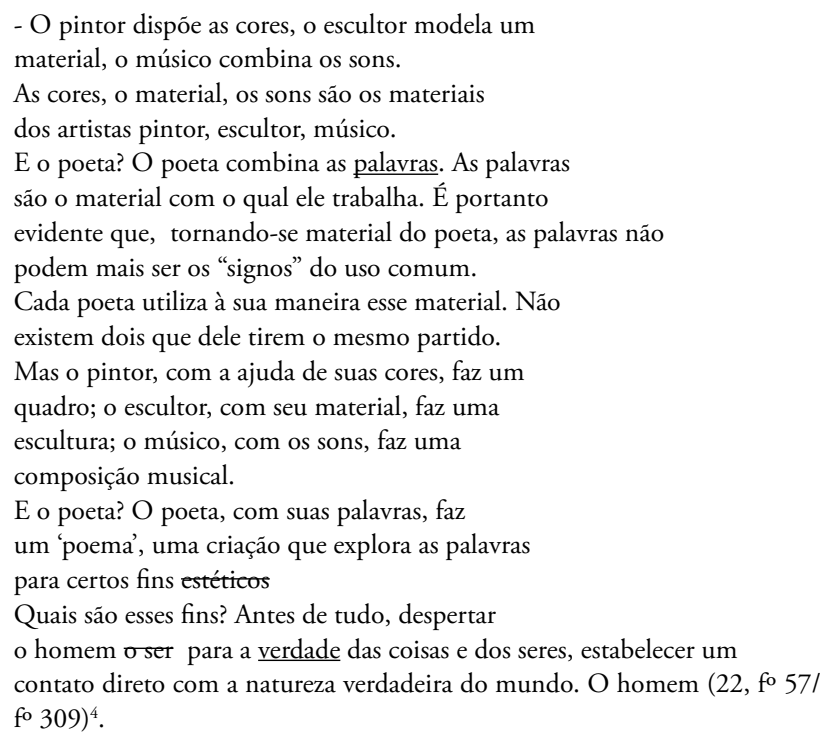

Em Semiologia da Língua, Benveniste (1989, p. 51-52) apresenta alguns sistemas de signos, dentre eles "[...] os signos da arte em suas variedades (música, imagens, reproduçóes plásticas) [...]”. Em seguida, o linguista traz dois aspectos da música: sua unidade de base, a nota, e seu modo de funcionamento, o eixo das simultaneidades e o eixo das sequências. Depois, passa para o domínio das artes ditas plásticas, também buscando sua unidade: "Mas qual pode ser a unidade da pintura ou do desenho? É a figura, o traço, a cor?” (BENVENISTE, 1989, p. 57). Sem precisar uma resposta, pois esta constitui para o linguista matéria de discussão, destaca que é a unidade que deve se fazer presente nos estudos que tenham a problemática da linguagem em seu cerne; isso porque "[...] nenhuma teoria séria poderá se constituir se ela se esquece ou se esquiva da questão da unidade, porque todo sistema significante deve se definir por seu modo de significação" (BENVENISTE, 1989, p. 57-58). A partir disso, passa a tecer consideraçóes acerca do funcionamento dos sistemas semiológicos ditos artísticos, como o da imagem e o do som, e das relaçôes significantes da linguagem artística.

4Para apresentação dos fólios, farei uso da transcrição diplomática (LAPLANTINE, 2008) em tradução para o português brasileiro. Nessa transcrição, conforme Laplantine (2011a), preservam-se a cor da caneta utilizada por Benveniste e os grifos por ele realizados. No final da transcrição, constam o número do envelope, a numeração do fólio no envelope e a numeração do fólio em relação ao número total de fólios (VIER, 2016). 
E a linguagem poética e o poeta apontados na nota do DB? Aparecem como traços dessa questão somente quando Benveniste esclarece que a natureza da homologia entre sistemas semióticos distintos pode variar: "[...] intuitiva ou racional, substancial ou estrutural, conceptual ou poética. 'Les parfums, les couleurs et les sons se répondent'. Estas 'correspondências' não estão senão em Baudelaire, elas organizam seu universo poético e a imagem que o reflete" (BENVENISTE, 2008, p. 61).

Em várias notas presentes no DB, Benveniste pensa a unidade e o material da linguagem poética. A partir disso, acredito que o poema - e questóes d/nele cruciais - está de certa forma presente em Semiologia da Língua no momento em que ao pensar a semiologia da língua em relação à semiologia da arte também o faz em seus manuscritos - a exemplo do excerto do DB aqui colocado.

\section{A natureza da linguagem poética}

No fólio 309, apresentado anteriormente, Benveniste está, a exemplo do que fez em Semiologia da Língua, pensando sobre o material de diferentes artistas: o pintor, o escultor, o músico e o poeta. É em comparação a outros artistas que o linguista delimita o material do poeta: a palavra.

No entanto, nos fólios 197 e 212, um dos que apresenta data, Benveniste pontua que ter a palavra como material de uma obra de arte não a coloca no mesmo patamar do material do músico ou do pintor, pois não se trata do mesmo sistema semiológico.

\section{$1 / 10 / 67$}

\section{A língua de Baudelaire}

Baudelaire é o poeta da interioridade do ser, de sua verdade profunda, dos sofrimentos do homem na natureza e na sociedade. Sua poesia visa a descrever a interioridade, as aspiraçôes, os sonhos, os delírios, as lembranças aplicando-lhes o estilo que convém à exterioridade. Não há nele tentativa de reduzir as palavras a um material que seria o equivalente dos sons para o músico, das cores para o pintor: será esforço de Mallarmé tratar a linguagem à maneira de um material sonoro. [...] (20, fo 3/ fo 197).

O poeta combina e distribui 


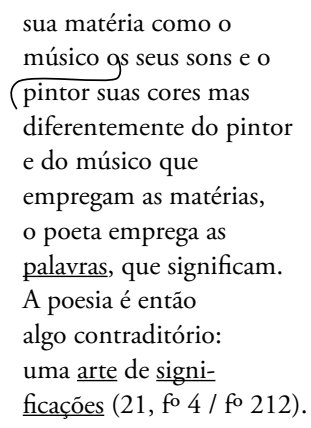

A palavra é o material do poeta porque ele a usa como um material. Destaco o como porque a palavra presente na poesia, em um primeiro momento, é a mesma do uso ordinário, com a significaçáo deste. No entanto, ao usá-la na poesia, é à vontade que o poeta a emprega, ou seja, a significação do uso ordinário não é um a priori para a produção poética. Talvez aí esteja a contradição: a arte em poesia está no obstáculo que a palavra impóe. Isso porque, repito mais uma vez, a palavra do poeta é a mesma do uso ordinário. E sobre esse uso ${ }^{5}$, Benveniste escreve:

O fato essencial é que o poeta constrói essa visão interior com palavras. Ele usa palavras como um material, ele as emprega à vontade e sem levar em conta o "uso".

Mas então duas possibilidades se oferecem teoricamente e foram ambas realizadas.

Uma é a de tratar essas palavras-materiais em vista de um efeito musical (frase-canto contínua onde a palavra perde sua individualidade), é o Mallarmé dos poemas, ou em vista de um efeito visual, por disposição e ao desafio da "gramática"

as palavras sobre a página, é o Mallarmé do Jogo de dados.

A outra é a de constituir um discurso a partir dessas palavras-materiais explorando as imagens que elas suscitam em virtude do sentido ou da sonoridade. O discurso será construído então sobre as imagens, e

5Em diálogo com Laplantine (2011b, 2008a), defendo que não há, no DB, uma oposição entre linguagem poética e linguagem ordinária. Ou seja, não há dois usos opostos que apresentem contrastes ou diferenças. (VIER, 2016). 

e ele unirá essas imagens produzidas pelas palavras em uma proposta coerente, que terá a estrutura "gramática" formal de um enunciado 'ordinário’. Esta é a língua poética de BAUDELAIRE (22, fo 66/ fo 318).

Assim, a palavra é o material do poeta enquanto palavra-material. Porque material, a palavra é utilizada tendo em vista, conforme a escrita de Benveniste, pelo menos, dois efeitos: seu efeito musical no verso e no poema, e seu efeito visual na disposição da página. Ou seja, espera-se que a palavra gere um efeito poético porque material do poeta. Além disso, porque material, a palavra, ao explorar as imagens, constitui um discurso. Ou seja, "o discurso será construído então sobre as imagens /e ele unirá essas imagens produzidas em palavras em uma proposta coerente".

E a palavra como material do poeta se relaciona com a palavra do uso ordinário. Essa relação é necessária para que a evocação e a emoçáo sejam possíveis. Nesse sentido, Benveniste escreve que a proposta coerente que encontramos nas palavras de Baudelaire dialoga com a gramática formal do uso ordinário. Mas não são as palavras do uso ordinário. E esta é a língua poética de Baudelaire: uma língua que evoca e emociona a partir da língua ordinária. Benveniste sublinha esse aspecto no fólio 350: "Na evocação a palavra é tratada como material". A palavra-material não diz da emoção, ela dá a emoção a partir da evocação, por isso material.

Benveniste também escreve que a palavra como material do poeta coloca em cena a escrita:

\author{
É preciso tratar as palavras \\ como materiais para \\ suscitar a visão, pois essa \\ visão é visão de alguma \\ coisa que ainda não foi \\ vista e o único meio que se \\ tem de fazê-la ver em \\ espírito é trabalhar as \\ que são \\ palavras o único intermediário \\ entre aquele que escreve e \\ aqueles que teem. \\ Mas então não se trata mais da linguagem, \\ é a escrita. (23, fo 16/ fo 339).
}

Porque a palavra é material do poeta, ela é o intermediário entre aquele 
que escreve e aquele que lê. Como bem esclarece Benveniste, a linguagem não é um instrumento de comunicação; logo, não é com a linguagem que o poeta trabalha. Poeta e linguagem são indissociáveis. Ao ter a palavra como material, o poeta trabalha com a escrita ${ }^{6}$ É a partir da escrita que o poeta pode tomar a palavra como material e produzir as imagens que evocaráo a experiência e suscitarão a emoção na língua poética.

E a unidade do poema? Podemos observar na escrita do linguista que esta é a palavra como ícone $e^{7}$.

O intentado em poesia é tudo: é o equivalente poético do 'raciocínio' ou da 'situação' que a prosa toma por objeto em geral.

O intentado poético é um estado poético, uma vibração particular da sensibilidade, a interiorização de uma sensação, de uma impressão.

É isso que governa a escolha das palavras pelo poeta: ele terá para escolher e associar as palavras mais vivas, as mais sugestivas, que suscitarão no leitor o mesmo o estado emocional cuja conversão em palavras o poeta tem como tarefa.

Isso quer dizer que a palavra é a unidade fundamental, mas uma unidade de natureza diferente daquela que é admitida para a palavra lexical. (22, fo 60/ fo 312).

O que o fólio 312 coloca em cena pela escrita de Benveniste é que a palavra poética, dada sua natureza icônica, suscita uma emoçáo, diferentemente da palavra lexical, cuja natureza suscita um pensamento. E é isto que governa a escolha das palavras: a vivacidade e a sugestão, pois será a partir disso que as palavras suscitaráo no leitor a emoçáo - tarefa maior do poeta. A palavra-ícone a partir da palavra-material precisa suscitar a emoção.

\footnotetext{
Em primeiro plano vem, obsessão desde o início desta reflexão, o problema da palavra.

A palavra é para o poeta uma coisa bem diferente do que é para o locutor. Há uma teoria da palavra na linguagem poética que ainda está para ser elaborada, mas que não começará a existir senão a partir do momento em que se tiver ab renunciado à noçấo da palavra
}

${ }^{6}$ Importante lembrar que Benveniste está fazendo referência aos poemas escritos por Baudelaire no livros As Flores do Mal. O linguista não está desconsiderando que haja poemas orais.

${ }^{7}$ Remeto aqui ao que Benveniste anota na Aula $8 \mathrm{em}$ Últimas Aulas no Collège de France (1968-1969): “[...] 'signo icônico' (ou 'simbólico', como se queira, a escolha dos termos independe totalmente da terminologia de Peirce) [...]” (BENVENISTE, 2014, p. 132). 
recebida da teoria da linguagem comum.

Isso resulta do fato de que o poeta pode escolher a palavra para dar a impressão da noçáo que ele quer exprimir: tulipa ou bondade ou tosão $\mathrm{e}$ milhares de outras podem, devidamente combinadas a outras palavras igualmente imprevisíveis, evocar poeticamente uma parte do céu ou o rosto da amada, ou qualquer outra coisa. (22, fo 29 / fo 281).

Benveniste escreve, nesse fólio, o quanto é difícil - ele chega a falar em obsessão - pensar a palavra na língua poética, pois é preciso abandonar o que se sabe sobre a palavra no uso ordinário. Vemos bem o quanto Benveniste retorna a esse tema e o quanto não é a razão que conduz a escolha das palavras em um poema, mas a emoção; não a objetividade do mundo, mas a subjetividade do homem.

2

Em que o poeta quer nos interessar? $\underline{\mathrm{Na}}$

natureza humana. Ele quer nos mostrar essa natureza nos fazer sentir que ela é nossa também.

(isso que é próprio do poeta)

Como ele vai fazer sentir - e não

dizer ou (o que não nos tocaria e que não é, de qualquer modo, o trabalho do poeta)? Por meio de uma linguagem especial, que não é mais a linguagem ordinária embora formada das mesmas unidades, mas um sistema próprio, organizado segundo suas próprias categorias e funçôes.

Essa linguagem deve referir-se a certa realidade. e duplamente particular

Essa realidade é sempre particular, ao mesmo tempo, porque ela é a realidade da poesia e porque ela é a realidade de um poeta. $\mathrm{Na}$ linguagem comum, a realidade é repres retratada pelo conjunto de signos que provê o inventário (o dicionáfio) da língua, com as escolhas e as frequênciąs relevantes de cada emprego (ordinário) da língua (ordinária).

A linguagem poética tem outra realidade, que, embora coincida materialmente com tal parte do inventário (8, fo $2 /$ fo 12$)$.

Como unidade, a palavra é a mesma do uso ordinário. No entanto, quando em uso, ou seja, quando no poema, a palavra é o ícone. Entendo, então, que não há duas línguas: uma língua ordinária e uma língua poética. Ao usar "poética" após "língua", Benveniste marca 
que a língua quando em estado de arte ${ }^{8}$ é diferente de quando ordinária: "língua poética" diz então que há uma realidade segunda instaurada pela língua em estado de arte: o universo poético. Da forma como leio, o universo poético é o discurso de Baudelaire - ou mesmo o discurso do poeta.

Como o que lemos em um poema é a escrita do poeta, é preciso acessar a língua em estado de arte para adentrar o discurso do poema (do poeta?) e então deixar-se tocar pela evocação e pela emoção suscitada pela arte. Para ler poeticamente, é preciso ultrapassar a noção de signo como princípio único, como bem diz Benveniste em Semiologia da Língua, e aventurar-se na linguagem, ou seja, na emoção e na experiência.

Em dois fólios produzidos em papel áspero verde-claro amarelado por isso a crença de que se trata de uma continuaçáo -, encontramos o que segue:

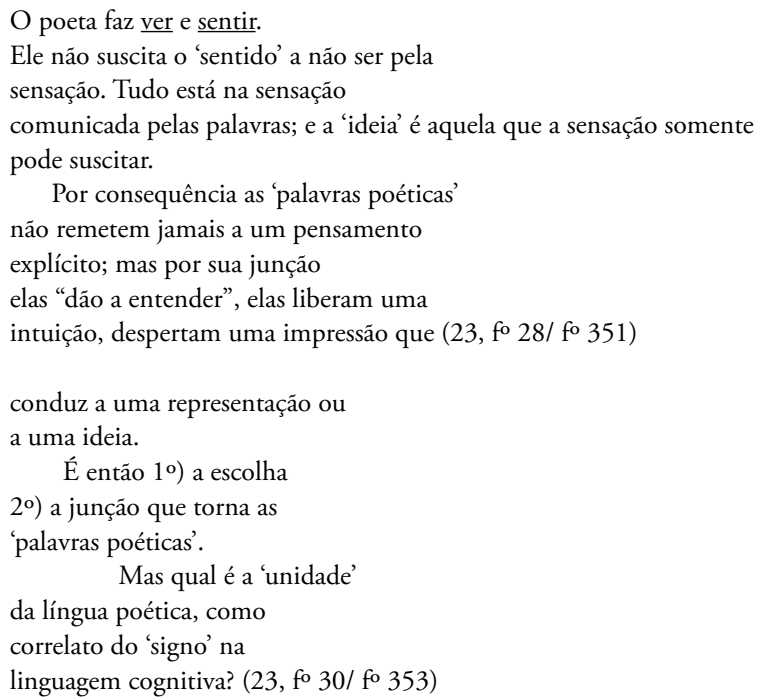

Esta questáo que Benveniste coloca parece respondida quando ele analisa os poemas de Baudelaire: pela escolha e junçáo das palavras poéticas é a imagem que aparece a partir das palavras utilizadas. Nesse viés, a palavra, porque intermediária entre o poeta e o leitor, funciona no poema como um

${ }^{8}$ Inspiro-me na expressão língua em estado de arte criada por Klafke (2015) para enunciar que diante de uma obra de arte a língua toca a linguagem como um dispositivo que permite ao homem sentir. Relacionando ao poema, a língua e a palavra, porque em estado de arte, suscitam no homem a emoção. 
ícone e náo como signo. A leitura poética não está para o reconhecimento de algo. A leitura poética está para a intuição de uma emoção ou de uma experiência: "tudo está na sensação/ comunicada pelas palavras". E se pudermos falar de uma ideia comunicada pelas palavras, será somente como uma sensação suscitada por elas e não como um pensamento explícito nelas.

\section{Consideraçóes Finais}

No primeiro contato que tive com o DB, fiquei encantada com a escrita de Benveniste presente nos fólios 196 e 195:

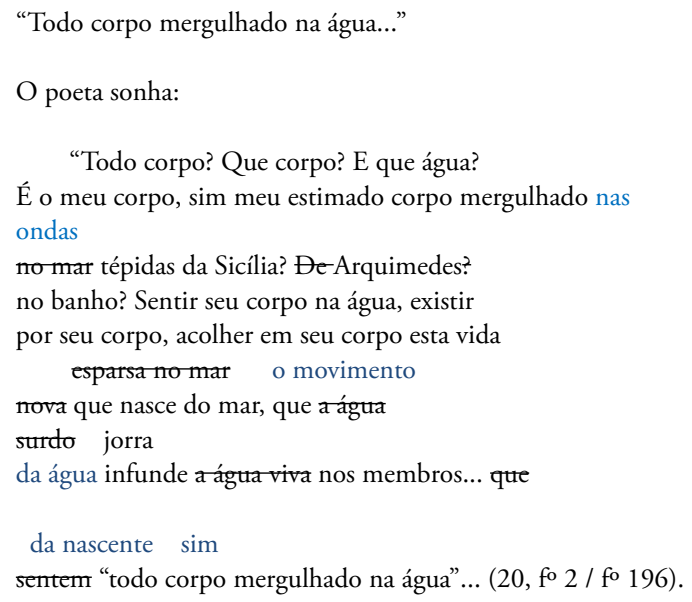

O cientista e o poeta

O cientista enuncia um teorema brilhante:

"Todo corpo mergulhado na água..."

O poeta sonha com essas primeiras palavras, carregadas

de uma estranha incerteza: "Todo corpo - que corpo? O corpo - tudo a ele retorna. Eu sinto meu corpo, mergulhado na água tépida da Sicília, esse doce toque da vaga em Siracusa. É lá que Arquimedes... ?” (20, fo 1 / fo 195).

Benveniste escreve sobre o cientista e o poeta a partir do princípio de Arquimedes, importante sábio grego que viveu entre 287 e 212 a.C. 
em Siracusa, Sicília, considerado por muitos o precursor do método experimental nas ciências exatas. Conta-se que Arquimedes, a pedido do rei de Siracusa, investigava se uma coroa, feita por um ourives, continha somente ouro - entregue pelo rei - ou se havia nela a presença de outro metal. Um dia, enquanto tomava banho, o sábio observou a água em movimento e teve a ideia de colocar uma barra de ouro exatamente igual à que o rei havia dado ao ourives em um recipiente com água. Em seguida, fez o mesmo com a coroa e coletou a sobra de água de ambos os recipientes. A sobra de água do recipiente com a coroa era menor do que com a barra de ouro. A partir disso, Arquimedes formula o princípio da impulsão: todo corpo mergulhado na água recebe deste uma impulsão vertical, de baixo para cima, de valor igual ao do peso do volume do líquido deslocado.

Acredito que não seja à toa que Benveniste escreve sobre o cientista e o poeta a partir de um corpo mergulhado na água. Um objeto afunda ou flutua na água dependendo da força de impulsão que este exerce sobre a água. Assim, proponho uma leitura para o fólio 195: a palavra do poeta terá sua significância dependendo da impulsão que as relações semiológicas propiciarem. Se, na leitura, o peso maior for o efeito ordinário, o sentido se dará a partir do uso ordinário. Se, na leitura, o peso maior for o efeito poético, o sentido se dará a partir da emoção e da imaginação.

Assim, entendo que Benveniste escreveu sobre o material e a unidade do poema para, por meio dessa escrita, problematizar a significação poética: a língua pode ser outra coisa ao mesmo tempo, ou seja, não é a palavra do uso ordinário, mas também não difere desta. Assim como um corpo na água, a palavra em poesia adentra a água, movimenta(-se) (n)a água, transborda.

\section{Referências}

BENVENISTE, É. Últimas aulas no Collège de France (1968 e 1969). Edição estabelecida por Jean-Claude Coquet e Irène Fenoglio. Trad. Daniel Costa da Silva et al. São Paulo: Editora Unesp, 2014.

. Dernières Leçons. Collège de France 1968 et 1969. Édition établie par Jean-Claude Coquet et Irène Fenoglio. Seuil: Gallimard, 2012.

. Baudelaire. Présentation et transcription de Chloé Laplantine. Limoges: Lambert-Lucas, 2011.

. [1969] Sémiologie de la langue. In: [1974] Problèmes de

linguistique générale, 2. Paris: Éditions Gallimard, 2008. p. 43-66. 
[1969] Semiologia da língua. In:

[1974] Problemas de

lingüística geral II. Campinas: Pontes, 1989. p. 43-67.

COQUET, J.; FENOGLIO, I. Introdução. In: BENVENISTE, É. Últimas aulas no Collège de France (1968 e 1969). Edição estabelecida por JeanClaude Coquet e Irène Fenoglio. Trad. Daniel Costa da Silva et al. São Paulo: Editora Unesp, 2014. p. 67-86.

DESSONS, G. La place du poème dans la théorie du discours. In: MARTIN, S. Émile Benveniste: pour vivre langage. Mont-de-Laval: IUFM Basse-Normandie, 2009. p. 71-81.

FENOGLIO, I. Manuscritos de linguistas e genética textual: quais os desafios para as ciências da linguagem? Exemplo através dos "papiers" de Benveniste. Tradução Simone de Mello de Oliveira, Verli Petri da Silveira, Zélia Maria Viana Paim. Santa Maria: UFSM, PPGL-Editores, 2013.

. La poétique d'Émile Benveniste. In: MARTIN, S. Émile Benveniste: pour vivre langage. Mont-de-Laval: IUFM Basse-Normandie, 2009. p. 25-38.

KLAFKE, S. R. Da (re)criaçáo enunciativa da experiência humana: a fotografia como testemunho. 2015. 102 f. Projeto de qualificação (Doutorado em Linguística Aplicada) -Programa de Pós-Graduação em Linguística Aplicada, Universidade do Vale do Rio dos Sinos (UNISINOS), São Leopoldo, 2015.

LAPLANTINE, C. Présentation. In: BENVENISTE, É. Baudelaire. Edição Chloé Laplantine. Limoges: Lambert-Lucas, 2011 a.

Lucas, 2011b.

. Émile Benveniste, l'inconscient et le poème. Limoges: Lambert-

Annexes. Fascicule 1 - Transcription diplomatique et reproduction des manuscrits inédits d'une poétique de Baudelaire par Emile Benveniste. Tese (Doutorado). Université Paris 8. Saint-Denis. 2008. Disponível em: <https://hal.archives-ouvertes.fr/tel-01228022/file/ annexesLAPLANTINE.pdf >. Acesso em: 13 maio 2012.

VIER, S. Quando a linguística encontra a linguagem: da escrita de Émile Benveniste presente no Dossiê Baudelaire ao estudo semiológico de uma obra literária. 2016. 176f. Tese (Doutorado em Linguística Aplicada) Programa de Pós-Graduação em Linguística Aplicada, Universidade do Vale do Rio dos Sinos (UNISINOS), São Leopoldo, 2016. 
. "Os perfumes, as cores e os sons se correspondem": Benveniste e a busca pela imagem criativa em Baudelaire. Desenredo, Passo Fundo, v. 14, n. 3, p. 515-540, set./dez., 2018. 